\author{
Authors \\ Lyn Guy \\ Research Student \\ School of Public Health \\ Griffith University \\ Meadowbrook Qld 4134 \\ Tel 0405344335 \\ Fax 0297481777 \\ Email L.Guy@gu.edu.au \\ Stephanie D. Short \\ Professor of Public Health \\ School of Public Health \\ Griffith University \\ Meadowbrook Qld 4134 \\ Tel 0733821024
}

Fax 0733821034

Email s.short@griffith.edu.au

\title{
Rehabilitation of Workers with Musculoskeletal Injury and Chronic Pain
}

Lyn Guy \& Stephanie D. Short

School of Public Health

Griffith University

\begin{abstract}
The aim of this study was to examine the relevance of type of work and socioeconomic status on the experiences of pain rehabilitation for workers with musculo-skeletal injuries. The paper reports results of a study conducted with patients $(n=20)$ and treating professionals $(n=40)$. The findings of this study provide insight into how patients with chronic musculo-skeletal pain and treating professionals determined success and also what they saw as barriers to success. Emergent themes and rich descriptions that supported the study, showed that patients' experiences were shaped significantly by social factors, and that type of work and socio-economic status were key determinants of success in terms of patients regaining their sense of independence and control over their lives - as opposed to losing control, remaining helpless and dependent on others, or becoming intent on revenge and validation of their pain and suffering.
\end{abstract}

Keywords: Blue-collar work, socio-economic status, chronic pain, musculoskeletal injury, rehabilitation

Word count: 4,056

Date received: 4 March 2005

Date accepted: 29 April 2005 


\section{Introduction}

Despite significant advances across the world in medicine and technological treatment of disease, chronic pain has 'remained an enigma that health care professionals often manage poorly' (Jacobson \& Mariano 2001: 241). Scientific evidence shows that despite a range of medical, therapeutic and multimodal biopsychosocial approaches, successful outcomes and long term benefits of treatment and management of chronic pain remain inconclusive, and the results of clinical trials are often contradictory (Smith 2000). Conclusions from an extensive review of the empirical research in relation to chronic pain arising from work-related musculoskeletal injury were that:

despite the progress that has been made in recent years, there continue to be a large number of individuals who are not adequately treated, and show quality of life is adversely affected by the various conditions collectively referred to under the rubric 'chronic pain'. It is now clear that the Cartesian mind-body dualism that has characterised earlier efforts to understand pain is no longer tenable, and will not advance our knowledge of pain....Chronic pain is a multidimensional problem that requires a multidimensional solution (Smith 2000: 36).

This mind-body dualism has been inherent in the medical model of treatment that characterises much of clinical practice in treating chronic pain (Bonica 1990). The biopsychosocial model was designed to overcome its limitations and is a recommended alternate strategy for more successfully managing the multiple dimensions that are associated with chronic pain (Bonica \& Loeser 2001, Engel 1977a, 1977b, IASP 1993, Jacobson \& Mariano 2001, Loeser \& Turk 2001, Melzack \& Wall 1996, Turk \& Okifuji 1999, Smith 2000, Wall 1999). Just how the integration of this model has influenced thinking amongst practitioners, however, is largely unknown.

Central to the biopsychosocial model is the tenet that the individual's self-report, the subjective narrative, is the key to understanding the multifactorial nature of chronic pain (Bonica 1990, Loeser \& Turk 2001, Turk \& Okifuji 1998, Turk \& Okifuji 1999, Wall 1999). This is opposed to the continued focus on objective biomedical factors that are relevant to management of acute pain that occurs soon after an injury. Whereas in acute pain the history of injury may match objective signs of injury and pathological changes in tissues, in chronic pain:

secondary effects...such as depression, physical deconditioning, social isolation, inappropriate medications, vocational dysfunction and superstitious beliefs about the body may be primary determinations of the patient's overall condition (Loeser \& Turk 2001: 2069).

This suggests that the underpinnings of primary care that maintain a focus on identifying objective signs of injury are not as secure as western biomedicine has believed (Bendelow \& Williams 1996). Accordingly, a successful biopsychosocial 
approach to chronic pain management is likely to require resolution of the traditional divide between the objective and the subjective, between positivistic approaches to clinical examination and an inductive understanding of the subjective values and meaning that each individual gives to their illness (Baszanger 1989, Bendelow \& Williams 1996, Bury 1982, Charmaz 1983, Engel 1977a, 1977b, Wall 1999). Maintenance of reductionist approaches to clinical decision making that characterise the medical model is likely to negate treatment effectiveness. Thus, seeking clinical information that primarily reflects medical practitioners' concerns with determining 'What is it?', has the potential to alienate clients and impose barriers to success (Armstrong 1994). Failure to acknowledge clients' perspectives and to give credence to their values in dealing with chronic pain is also likely to exacerbate their condition (Kouyanou, Pither \& Wessely 1997). Further decline in clients' conditions can occur, in fact, as a result of their experiences in the clinical setting (Illich 1977).

The biopsychosocial approach, by contrast, involves the adoption of a holistic and systematic perspective in assisting people with chronic pain (Engel 1977a, 1977b, Engelbart \& Vranken 1984, Jacobson \& Mariano 2001, von Bertalanffy 1968, Wall 1999). This includes consideration of macro socio-structural conditions that are largely determined by socio-economic and political processes (Berkman, Glass, Brissette \& Seeman 2000). It also recognises the significance of socio-cultural and psychosocial factors in determining health outcomes. Berkman et al. (2000) have reviewed empirical research that has examined the role of socio-economic factors and social support in relation to conditions such as depression, and the aging process. However, these influences have not previously been considered in the context of chronic pain. In fact, this is the first study to examine the rehabilitation experiences of injured workers with chronic musculoskeletal pain in relation to their occupational backgrounds and socioeconomic status.

Chronic pain, by definition, is characterised by the persistence of pain for at least three months, often beyond six months or more, so that the initial period of expected healing of the original injury has passed (Bonica \& Loeser 2001). In Australia, chronic pain is strongly associated with socio-economic disadvantage, high levels of unemployment and significant social costs (Blyth, March, Brnabic, Jorm, Williamson \& Cousins 2001). In this study, chronic pain was significantly associated with: female gender, lower levels of education, not having private health insurance, receiving disability benefit or unemployment benefit, having poor rated health, being unemployed for health reasons, and being psychologically distressed. Chronic pain is also strongly associated with social disadvantage. New South Wales WorkCover figures confirm that where injured workers have not been able to return to work within twelve months after an injury, as is the case for many with chronically painful musculoskeletal injuries, then their ongoing chances of re-gaining employment are minimal (Rogerson 2003). This means the personal costs experienced by injured workers with chronic pain arising from musculoskeletal conditions are often immense. Others are also significantly affected. Employers, for example, incur increasing costs in terms of 
sick leave, lost production, recruitment and retraining and social welfare services bear the costs associated with supporting people with work-related disabilities whose claims for long-term workers' compensation payments are refused by insurance companies.

\section{The study's purpose and methodology}

The purpose of the study was to investigate the meanings of chronic pain perceived by both workers with musculoskeletal injury and their treating practitioners at a multidisciplinary pain clinic. This involved examining the significance of the kind of work performed by the injured workers who participated in the study and their socio-economic background. The study questioned injured workers and practitioners about what they saw as success in the management of their injuries and their pain, and the barriers to achieving it. Participants were recruited through the multidisciplinary pain clinic. Attendance at such a clinic usually indicates that sufferers have come to the 'end of the road' in terms of seeking treatment (Bendelow \& Williams 1996, Bonica 2001, Loeser \& Turk 2001).

A qualitative approach, informed by a naturalistic interpretive paradigm (Denzin 2001, Denzin \& Lincoln 2000), was adopted and a series of in-depth participant interviews was undertaken with professionals and injured workers with chronic musculoskeletal pain to explore perceptions of both parties. The main aim was to compare how they perceived success in response to medical and therapeutic interventions and what they saw as barriers to successful management in chronic musculoskeletal pain.

\section{Data collation and coding}

The in-depth interviews were conducted over an 18 month period between 1998 and 2000 in Sydney. These included interviews with injured workers with chronic musculoskeletal pain $(n=20)$, many of whom were undergoing workplace based rehabilitation $(\mathrm{n}=8)$, and with members of a chronic pain support group who participated in a focus group activity $(n=20)$. The majority of these participants were from blue-collar backgrounds (92\%), including labouring, production-line and heavy industrial occupations. The remainder were from middle management $(8 \%)$. Twelve interviews were undertaken with medical practitioners who specialised as anesthetists $(n=3)$, rheumatologists $(n=2)$, psychiatrists $(n=2)$, occupational physicians $(n=2)$ and general practitioners $(n=3)$. Twenty eight interviews were also conducted with allied health professionals including psychologists, physiotherapists, occupational therapists, rehabilitation consultants and nurses. All interviews were taped and transcribed. This triangulation of data sources added to the rigour and reliability of the methodology and data collection processes (Patton 2002) that were used in this qualitative research.

Sampling continued with each participant group until saturation occurred, that is, until no new issue or concept was identifiable in participants' responses. Review of the transcribed texts was undertaken using a combination of deduction, where 
the theory guides the data, and induction, where the theory is seen to emerge from the data (Layder 1998).

\section{Findings}

The findings were obtained by piecing together information using the method of bricolage. Here the researcher takes on the role of the 'bricoleur', making use of the insights and information that have been collected both in the course of the study and throughout one's life, in order to piece together the diverse and complex meanings that emerge in the data (Kincheloe 2001, Patton 2002). Bricolage includes the processes undertaken by the interpreter in problemsolving and transforming the data into meaningful information (Denzin \& Lincoln, 2000; Patton 2002). This involves the development of typologies as described by sociologist, Derek Layder (1998). According to him, there are three main processes of data analysis that are required in such an approach. These are: identifying key concepts; forming conceptual clusters and networks; and forming typological models. This three-tier process of interpretation and analysis is akin to the open and axial coding processes and development of emergent themes that were identified from the data. The thematically determined issues that were apparent in the feedback from individual injured workers and doctors are presented below.

The findings of this study provided insight into how injured workers with chronic pain and treating professionals understood success and also what they saw as barriers to success. Emergent themes and rich descriptions that supported the analysis showed that workers' experiences were shaped significantly by social factors, and that social influences were key determinants of success in terms of how individuals regained their sense of independence and control over their lives - as opposed to losing control, remaining helpless and dependent on others, or becoming intent on revenge and validation of their pain and disability.

Three distinct groups emerged:

1. those who were 'disempowered', depressed and who became increasingly dependent upon social benefits and ongoing health care;

2. those who were able to become 'empowered' through social mobility; and

3. those seeking validation of their injury by remaining 'angry and intent on revenge', and by pursuing justice through ongoing litigation.

\section{Disempowered injured workers}

In the disempowered group, all had left school early. They had very little formal education and had started paid work at a relatively early age. Disempowered participants were predominantly unskilled and the work they had undertaken was physically demanding or they were performing tasks that were repetitive in nature. This meant that their options for moving into other less demanding work were limited by their lack of education, skills, and ongoing physical limitations due to the ongoing effects of their injury. For these participants, rehabilitation had resulted in several failed return-to-work programs that added to their sense of 
helplessness, loss of control, depression and disempowerment. As one injured worker proclaimed:

But the work in a chicken factory is hard work. It's repetitive and there's no stopping. They give you a break for tea-time and a lunch break, but it's not enough. I think I've been at work for too long doing things that have broken down my body. You can't turn back the clock. So what do you do?

\section{Empowered}

Alternatively, many of those in the empowered group, although they also had undergone similar attempts to help them return to their previous line of work without long term success, had overcome these barriers. They were able to identify a new future career and identity. Failure to regain full time work or their previous employment was common but they differed from their disempowered counterparts in the ways in which they reacted to such a situation. One such participant who had been off work for two years, having continued to participate in a 'light duties' program at work for about twelve months, and for whom the traditional approaches had been unsuccessful, stated:

I'm doing my own rehab now - I'm actually back at Uni retraining myself because I can't do what I did before. So the rehab didn't work for me. I'm doing my own rehab now.

Those who were able to become 'empowered' had more advantaged socioeconomic backgrounds and higher levels of education. They tended to be employed as white-collar workers prior to their work injuries. They were not defeated by their experiences with failed return-to-work programs. Rather, they decided on new career paths regardless of the decisions of rehabilitation providers or insurance company decisions. These workers were not commonly referred to rehabilitation in relation to their ongoing pain and disability.

\section{3. 'Angry and seeking revenge'}

The third group - those who were 'angry and seeking revenge' - consistently experienced return-to-work rehabilitation processes that they found unsatisfactory. This fuelled their intent to pursue litigation, a means by which they could seek revenge for being disabled by their ongoing pain experiences. There was a strong sense of grievance and discontent among these participants regarding their rehabilitation experience. As one injured worker commented: 'they tried to have me go back to the same work that caused my pain in the first place'. Indeed, such rehabilitation, was seen as useless: 'it only made my condition worse', and caused further insult. Rehabilitation professionals were regarded as inexperienced: 'just out of college', and more interested in 'pleasing the boss' and 'representing the insurance company' than in assisting injured workers. For these workers, their rehabilitation experiences and difficulties with insurance companies added to a lack of trust in, and cynicism about, what 'the system' and rehabilitation had to offer. Their experiences of being let down by others and of trying to work 'despite the pain', only intensified their anger. 
All participants in this group confirmed that third-party and workers' compensation systems were instrumental in disrupting their lives, particularly those caught up in litigation processes. Professionals confirmed that the process itself is very distressing' and this was inherently difficult for all injured workers 'because they have to prove there's a problem and the problem is difficult to prove because it's a pain problem. There are all sorts of hoops which they have to jump through'. This meant that the procedures that injured workers confronted in having to 'prove' the legitimacy of their pain and injury were very distressing. As one medical specialist commented, participants in this group were often intent on pursuing litigation as a means of seeking justice rather than on undertaking rehabilitation that focused on returning to employment:

Ultimately what the insurer wants is a return-to-work outcome, but often this is not in the best interest of the patient. If they see that work caused their problems, then often they will see this as adding insult to injury, particularly if the insurer becomes insistent on it. It's a matter of seeking justice for the suffering and insult.

As a result, when the insurance company insisted on return to work, injured workers were more likely to focus on 'seeking justice for the suffering and insult'. For some, the pursuit of justice became more important to workers than complying with the insurer's demands for them to return to the work, particularly since that type of work had created their injury and subsequent pain and disability.

\section{Discussion and conclusion}

According to the interviews with practitioners and injured workers, blue-collar work disadvantaged injured workers. Many practitioners reported that blue-collar workers who incur chronically painful musculoskeletal injuries at work 'don't have much more to lose'. They have physically demanding, low paid jobs and come from low socio-economic backgrounds that render their chances of recovery and return to work virtually non-existent. Under current pain management and rehabilitation service provision they are set up for failure.

The cluster of themes that emerged from the data reflected the importance of pre-injury occupation and work tasks on injured workers. This was described by treating professionals in terms of the 'line of employment which predisposes them to these kinds of injuries, chronic pain and compensation'. The socioeconomic background of injured workers was also an important factor in relation to recovery from these injuries, as the comment by a rehabilitation consultant indicates:

These clients all have low socio-economic backgrounds - by way of their line of employment which predisposes them to these kinds of injuries, chronic pain and compensation. So by the time they report their injury they are in big trouble, by the time they lose more money on the compensation 
system, then they don't have much more to lose. Time is their worst enemy.

As this comment suggests, by having a background in process work, in labouring or in other blue-collar occupations, workers were more likely to become injured and to experience the injurious effects of their work before they actually registered their injury and sought medical help. These findings were consistent with reports from WorkCover NSW that the most common injures are related to blue-collar tasks such as manual handling (34.6\%), resulting in musculoskeletal sprains and strains (Rogerson 2003).

The relationship between previous work status, occupation and socio-economic status was further summarised by a treating psychologist:

These people who are from lower socio economic groups who are involved in the sort of work which predisposes them to musculoskeletal pain problems which doesn't mean we don't see white collar workers very often, or say those who slip in the supermarket or on the stairs at work and may incur pain problems, but the fact of the matter remains those from higher socio-economic groups have more options - options for rehabilitation, for changing jobs, alternate courses of income or self education. Clearly it has an impact - particularly their self-esteem. For lots of people whose self esteem is tied up with their physical prowess and this is tied up in their work now can't do it - are very stressed and cut up about it. So you can't look at the whole picture of chronic pain without looking at it.

Clearly, chronic pain is strongly associated with socio-economic disadvantage, high levels of unemployment and social costs. Further, the 'iatrogenic' effects of injured workers' experiences of compensation systems have potential to further disadvantage them if they have blue-collar backgrounds. Indeed, the study's results show that workers from blue-collar backgrounds experience a double jeopardy in relation to disabling work injury and its management. First, the type of heavy and repetitious work performed by blue-collar workers is more likely to predispose them to musculoskeletal injury. Second, because they have fewer resources on which to draw, such as education and job skills, their capacity to retrain and to regain full employment as required by current compensation and rehabilitation programs is severely constrained. Their experience of work-related rehabilitation is unlikely to be an empowering one.

These findings are consistent with the results of other studies which have also found that chronic pain is associated with socio-economic disadvantage and high levels of unemployment in Australia (Blyth et al. 2001). They also support claims that chronically painful work-related injuries are imposing growing costs not only on those who incur them but on the community more broadly (Woolf \& Pfleger 2003). 


\section{References}

Armstrong, D. (1994) Outline of Sociology as Applied to Medicine $4^{\text {th }}$ Ed. Butterworth Heinemann: London.

Baszanger, I. (1989) 'Pain: its experience and treatments' Social Science \& Medicine 29 (3): 425-434.

Berkman, L.F., Glass, T., Brissette, I. \& Seeman, T.E. (2000) 'From social integration to health: Durkheim in the new millennium' Social Science \& Medicine $51(3): 843-857$.

Bendelow, G. \& Williams, S.J. (1996) 'The end of the road? Lay views on a pain relief clinic' Social Science \& Medicine 43 (7): 1127-1136.

Blyth, F.M., March, L.M., Brnabic, A.J.M., Jorm, L.R., Williamson, M. \& Cousins, M. (2001) 'Chronic pain in Australia: a prevalence study' Pain 89 (2-5):127-134.

Bonica, J. (1990) The Management of Pain Philadelphia: Lea \& Felbiger.

Bonica, J. (2001) 'Introduction' in J.D. Loeser, S.H. Butler, C.R. Chapman \& D.C. Turk (eds). Bonica's Management of Pain $3^{\text {rd }}$ Ed. Philadelphia: Lippincott Williams \& Wilkins.

Bonica, J. \& Loeser, J. D. (2001) 'History of pain concepts and therapies' in J. D. Loeser, S.H. Butler, C.R. Chapman \& D.C. Turk (eds) Bonica's Management of Pain $3^{\text {rd }}$ Ed. Philadelphia: Lippincott Williams \& Wilkins.

Bury, M. (1982) 'Chronic Illness as biographical disruption' Sociology of Health \& Illness 4(2): 167-182.

Charmaz, K. (1983) 'Loss of self: a fundamental form of suffering in the chronically ill' Sociology of Health \& Illness 5(2):168-195.

Denzin, N. (2001) Interactive Interactionism $2^{\text {nd }}$ Ed. Thousand Oaks, California: Sage Publications.

Denzin, N.K. \& Lincoln, Y.S. (2000) 'Introduction: the discipline and practice of qualitative research' in N.K. Denzin and Y. S. Lincoln (eds) Handbook of Qualitative Research 2nd Ed. Thousand Oaks, California : Sage Publications.

Engel, G. (1977a) 'The need for a new medical model: a challenge for biomedicine' Science Vol. 196: 129-136.

Engel, G. (1977b) 'The biopsychosocial model and the education of health professionals' Annals New York Academy of Sciences Vol.169: 169 -181. 
Engelbart, H.J. \& Vranken, M.A.E. (1984). 'Chronic pain from the perspective of health: a view based on systems theory' Social Science \& Medicine 19 (12): $1383-1392$.

IASP (1993) 'Assess the person, not just the pain' Pain International Association for the Study of Pain: Clinical Updates September 1(3).

Illich, I. (1977) Limits To Medicine, Medical Nemesis: The Expropriation of Health London: Penguin Books.

Jacobson, L. \& Mariano, A. J. (2001) 'General considerations of chronic pain' in J.D. Loeser, S.H. Butler, C.R. Chapman \& D.C. Turk (eds) Bonica's Management of Pain $3^{\text {rd }}$ Ed. Philadelphia: Lippincott Williams \& Wilkins.

Kincheloe, J.L. (2001) 'Describing the bricolage: conceptualizing a new rigor in qualitative research' Qualitative Inquiry Vol. 7: 679-692.

Kouyanou, K., Pither, C.E., \& Wessely, S. (1997). 'latrogenic factors and chronic pain' Psychosomatic Medicine 59 (6): 597-604.

Layder, D. (1998) Adaptive Theory in Sociological Practice London: Sage.

Loeser, J.D., \& Turk, D.C. (2001) 'Multidisciplinary pain management' in J.D. Loeser, S.H. Butler, C.R. Chapman \& D.C. Turk (eds) Bonica's Management of Pain $3^{\text {rd }}$ Ed. Philadelphia: Lippincott Williams \& Wilkins.

Melzack, R. \& Wall, P. (1996) The Challenge of Pain $2^{\text {nd }}$ Ed. New York: Penguin. Patton, M.Q. (2002) Qualitative Research \& Evaluation Methods $3^{\text {rd }}$ Ed. London: Sage Publications.

Rogerson, S. (2003) 'Development of work related activity programs to enhance return to work outcomes' Paper presented at Pain Management and Rehabilitation: Establishing Best Practice Seminar WorkCover NSW: Sydney.

Smith, B. (2000) Chronic Pain Initiative: Report of the Chair of the Chronic Pain Panels Chronic Pain Panels for the Ontario Workplace Safety \& Insurance Board: Ontario Canada.

Turk, D.C. \& Okifuji, A. (1998) 'Directions in prescriptive chronic pain management based on diagnostic characteristics of the patient' APS Bulletin 8(5):1-16

Turk, D.C. \& Okifuji, A. (1999) 'Assessment of patient's reporting of pain: an integrated perspective' Lancet Vol. 353:1784-88.

von Bertalanffy, L. (1968) General Systems Theory New York: George Brazilier. Wall, P. (1999) Pain: The Science of Suffering Great Britain: Phoenix. 
Woolf, A.D. \& Pfleger, B.P. (2003) 'Burden of major musculoskeletal conditions' Bulletin of World Health Organization 81 (9): 646-56. 